American Journal of Applied Sciences 8 (1): 77-81, 2011

ISSN 1546-9239

(C) 2010 Science Publications

\title{
Improving Power System Transient Stability with Static Synchronous Series Compensator
}

\author{
Prechanon Kumkratug \\ Division of Electrical Engineering, Faculty of Engineering at Si Racha, \\ Kasetsart University, 199 M.6, Tungsukhla, Si Racha, Chonburi, 20230, Thailand
}

\begin{abstract}
Problem statement: Modern power system consists of the complicated network of transmission lines and carries heavy demand. Thus they cause in the stability problem. One of the major interests of power utilities is the improvement of power system transient behavior. Approach: Static Synchronous Series Compensator (SSSC) is a power electronic based device that has the capability of controlling the power flow through a line. This study applies the SSSC to improve transient stability of power system. To verify the effect of the SSSC on transient stability, the mathematical model and control strategy of a SSSC is presented. The SSSC is represented by variable voltage injection with associate transformer leakage reactance and the voltage source. The series voltage injection model of SSSC is modeled into power flow equation and thus it is used to determine its control strategy. This study uses machine speed deviation to control it. The swing curves of the three phase faulted power system without and with a SSSC is tested and compared in various cases. Results: The swing curve of system without a SSSC gets increases monotonically and thus the system can be considered as unstable whereas the swing curves of system with a SSSC can be considered as stable. Conclusion: SSSSC can improve transient stability of power system.
\end{abstract}

Key words: Power system stability, transient stability, FACTS devices, static synchronous series compensator, generating stations, Static Synchronous Series Compensator (SSSC), Single Machine Infinite Bus (SMIB), transformer leakage, voltage injection, voltage source

\section{INTRODUCTION}

From the energy utilization point of view, electricity is still being regarded as mighty means of energy carrier. Nowadays, the demand of electricity has dramatically increased and a modern power system becomes a complex network of transmission lines interconnecting the generating stations to the major loads points in the overall power system in order to support the high demand of consumers. The complicated network causes the stability problem. Transient stability improvement is one of the important aspects in modern power system (Al-Rawi et al., 2007; Babainejad and Keypour, 2010; Sahoo et al., 2010; Parry and Gangatharan, 2005). They have proposed many methods to improve stability of power system such as load shedding, High Voltage Direct Current (HVDC), Flexible AC Transmission system (FACTS), (Hannan and Chan, 2006; Chettih et al., 2008; Seyed et al., 2008a).

A Static Synchronous Series Compensator (SSSC) is a member of the FACTS family that is connected in series with power system. The SSSC consists of a solid state voltage source converter with GTO thyristor switches or other high performance of semi-conductor and transformer. The SSSC can electrically mimic reactor and capacitor by injecting a shunt current in quadrature with the line voltage. The reactive power (or current) of the SSSC can be adjusted by controlling the magnitude and phase angle of the output voltage of the shunt converter (Al-Husban, 2009; Seyed et al., 2008b).

This study presents the method of improving transient stability of power system using a SSSC. The mathematical model of power system equipped with a SSSC is systematically derived. The presented mathematical model is applied to design control strategy of a SSSC. The simulation results are tested on a Single Machine Infinite bus system. The effect of gain control of a SSSC on stability improvement is also investigated.

\section{MATERIALS AND METHODS}

Mathematical model: Figure 1a shows the single line diagram of Single Machine Infinite Bus (SMIB) system without a SSSC and the corresponding equivalent circuit is shown in Fig. 1b. Here $X_{1}$ is the equivalent reactance between the machine internal bus and the bus $\mathrm{m}$ and $\mathrm{X}_{2}$ is the equivalent reactance between bus $\mathrm{m}$ and the infinite bus. The generator is represented by a constant voltage source (E') behind transient reactance $\left(\mathrm{X}_{\mathrm{d}}^{\prime}\right)$. 
Am. J. Applied Sci., 8 (1): 77-81, 2011

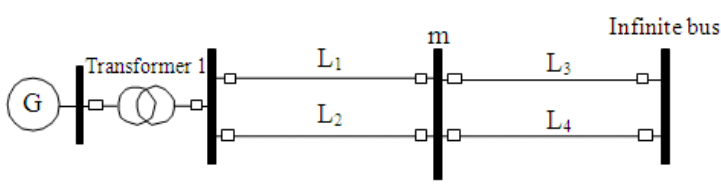

(a)

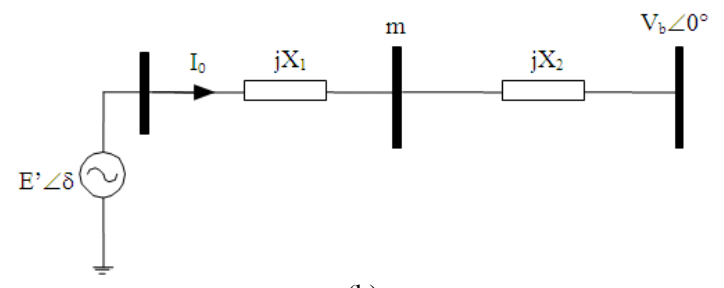

(b)

Fig. 1: Single machine infinite bus system schematic diagram (b) equivalent circuit

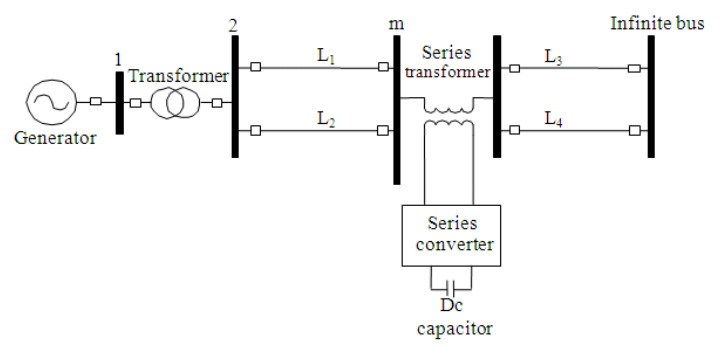

(a)

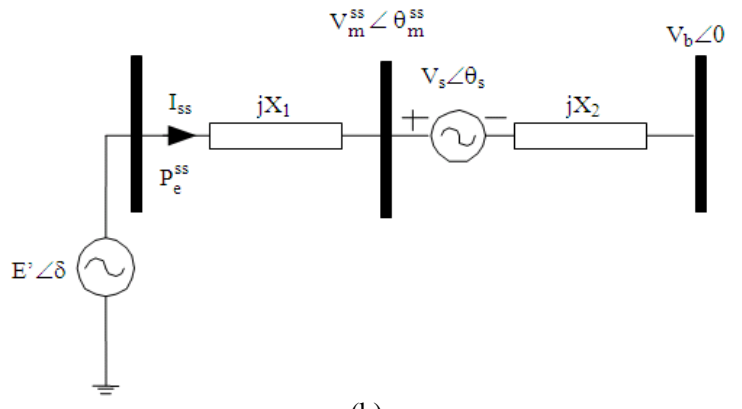

(b)

Fig. 2: Single machine infinite bus system with a SSSC (a) schematic diagram (b) equivalent circuit of system with a SSSC represented by a series voltage injection

Consider the system without a SSSC as shown in Fig. 1, the line current is given by:

$$
\begin{aligned}
& \mathbf{I}_{0}=\frac{E^{\prime}-V_{b}}{j X} \\
& =\frac{\left(E^{\prime} \cos \delta+j E^{\prime} \sin \delta\right)-\left(V_{b}\right)}{j X} \\
& =\left(\frac{E^{\prime}}{X} \sin \delta\right)+j\left(-\frac{E^{\prime}}{X} \cos \delta+\frac{V_{b}}{X}\right)
\end{aligned}
$$

Here $X=X_{1}+X_{2}$ :

$\theta=\tan ^{-1}\left[\frac{V_{\mathrm{b}}-\mathrm{E}^{\prime} \cos \delta}{\mathrm{E}^{\prime} \sin \delta}\right]$

The output electrical power of the system without a SSSC is given by:

$$
\mathrm{P}_{\mathrm{e}}^{0}=\frac{\mathrm{E}^{\prime} \mathrm{V}_{\mathrm{b}}}{\mathrm{X}} \sin \delta
$$

Now, consider the system with a SSSC as shown in Fig. 2. The Fig. $2 b$ represents the equivalent circuit of Fig. 2a. The SSSC is represented by a series voltage injection $\left(\mathrm{V}_{\mathrm{s}}\right)$ and transformer leakage reactance. From Fig. $2 b$, the line current of the system with a SSSC is given by:

$$
\mathbf{I}_{\mathrm{ss}}=\frac{\mathbf{E}^{\prime}-\mathbf{V}_{\mathrm{s}}-\mathrm{V}_{\mathrm{b}}}{\mathrm{jX}}=\left[\frac{\mathbf{E}^{\prime}-\mathrm{V}_{\mathrm{b}}}{\mathrm{jX}}\right]+\left[\frac{-\mathbf{V}_{\mathrm{s}}}{\mathrm{jX}}\right]
$$

From the Eq. 1 and 4, the line current of the system with a SSSC is given by:

$$
\mathbf{I}_{\mathrm{ss}}=\mathbf{I}_{0}+\Delta \mathbf{I}
$$

Here $\Delta \mathbf{I}=\frac{-\mathbf{V}_{\mathrm{s}}}{\mathrm{jX}}$

From Eq. 1 and 4, $\Delta \mathrm{I}$ is the additional component of the system of a SSSC. The output electrical power equation of generator can be expressed by:

$$
\begin{aligned}
& \mathrm{P}_{\mathrm{e}}^{\mathrm{ss}}=\operatorname{Re}\left[\mathbf{E}^{\prime}\left(\mathbf{I}_{\mathrm{ss}}\right)^{*}\right] \\
& =\operatorname{Re}\left[\mathbf{E}^{\prime}\left(\mathbf{I}_{\mathbf{0}}\right)^{*}\right]+\operatorname{Re}\left[\mathbf{E}^{\prime}(\Delta \mathbf{I})^{*}\right]
\end{aligned}
$$

The first term of Eq. 6 represents the system without a SSSC. The second term is the additional component from the $\operatorname{SSSC}\left(\Delta \mathrm{P}_{\mathrm{e}}^{\mathrm{ss}}\right)$ rewritten by:

$\mathrm{P}_{\mathrm{e}}^{\mathrm{ss}}=\mathrm{P}_{\mathrm{e}}+\Delta \mathrm{P}_{\mathrm{e}}^{\mathrm{ss}}$

The $\Delta \mathrm{P}_{\mathrm{e}}^{\mathrm{ss}}$ is written by:

$$
\begin{aligned}
& \Delta \mathrm{P}_{\mathrm{e}}^{\mathrm{ss}}=\operatorname{Re}\left[\mathbf{E}^{\prime}\left(\frac{-\mathbf{V}_{\mathrm{s}}}{\mathrm{j} \mathrm{X}_{2}}\right)^{*}\right]=\operatorname{Re}\left[\mathrm{E}^{\prime} \angle \delta\left(\frac{-\mathrm{V}_{\mathrm{s}} \angle \theta_{\mathrm{s}}}{\mathrm{j} X}\right)^{*}\right] \\
& =\frac{\mathrm{E}^{\prime} \mathrm{V}_{\mathrm{s}}}{\mathrm{X}} \sin \left(\delta-\theta_{\mathrm{s}}\right)
\end{aligned}
$$


When $\mathrm{V}_{\mathrm{s}}$ is positive, the SSSC supplies the reactive power to the system, it is called capacitive mode and then the series voltage angle $\theta_{\mathrm{s}}$ is in lagging with the line current as shown in Fig. $3 b$ whereas $V_{s}$ is negative, the SSSC absorbs the reactive power to the system, it is called reactive mode and then the series voltage angle $\theta_{\mathrm{s}}$ is in leading with the line current as shown in Fig. 3c. With the capacitive mode the Eq. 8 is given by:

$\Delta \mathrm{P}_{\mathrm{e}}^{\mathrm{ss}}=\frac{\mathrm{E}^{\prime} \mathrm{V}_{\mathrm{s}}}{\mathrm{X}} \cos (\delta-\theta)$

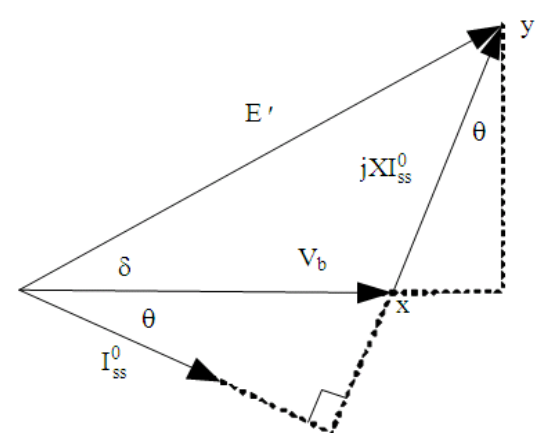

(a)

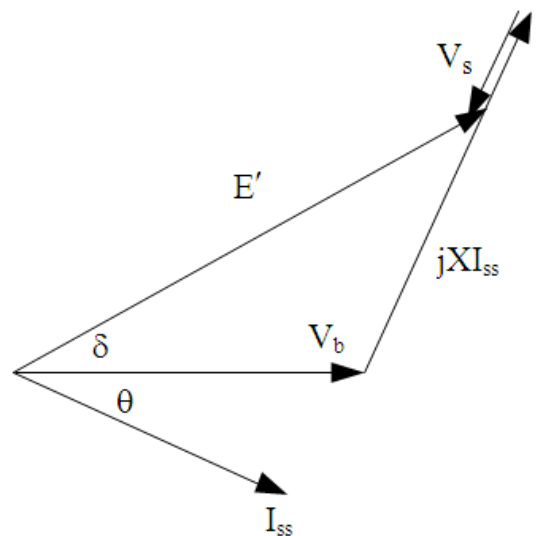

(b)

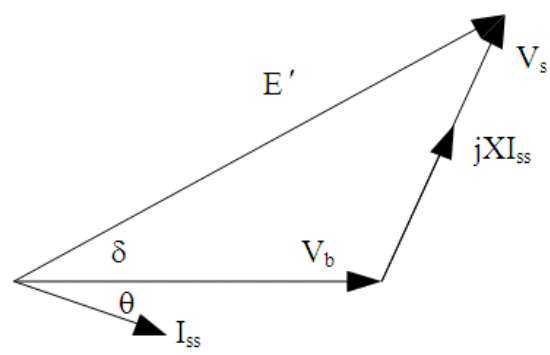

(c)

Fig. 3: Phasor diagram (a) without a SSSC (b) with a SSSC operating in capacitive mode (c) with a SSSC operating in reactive mode
From the Eq. 2, it can be written by:

$\mathrm{E}^{\prime} \sin \delta \sin \theta=\mathrm{V}_{\mathrm{b}} \cos \theta-\mathrm{E}^{\prime} \cos \delta \cos \theta$

With some mathematical manipulations of Eq. 10, it can be written by:

$\cos (\delta-\theta)=\frac{V_{b}}{E^{\prime}} \cos (\theta)$

From the phasor diagram as shown in Fig. 3, it indicates that the SSSC doesn't change the line current angle. However, the SSSC affects on the line current magnitude. When $\mathrm{V}_{\mathrm{s}}$ lags line current $90^{\circ}$, the line current magnitude is increased and when $\mathrm{V}_{\mathrm{s}}$ leads line current $90^{\circ}$, the line current magnitude is decreased as can be seen in Fig. 3 .

From the Fig. 3, the cosine of the line current angle is given by:

$$
\begin{aligned}
\cos (\theta) & =\frac{E^{\prime} \sin (\delta)}{x y} \\
& =\frac{E^{\prime} \sin (\delta)}{\sqrt{\left(E^{\prime}\right)^{2}+\left(V_{b}\right)^{2}-2 E^{\prime} V_{b} \cos (\delta)}}
\end{aligned}
$$

From Eq. 9 and 12, the additional component of output electrical power is:

$$
\Delta \mathrm{P}_{\mathrm{e}}^{\mathrm{ss}}=\frac{\mathrm{V}_{\mathrm{s}} \mathrm{E}^{\prime} \mathrm{V}_{\mathrm{b}}}{\mathrm{X} \sqrt{\left(\mathrm{E}^{\prime}\right)^{2}+\left(\mathrm{V}_{\mathrm{b}}\right)^{2}-2 \mathrm{E}^{\prime} \mathrm{V}_{\mathrm{b}} \cos \delta}} \sin \delta
$$

From Eq. 7 and 13, the output electrical power of system with a SSSC is given by:

$\mathrm{P}_{\mathrm{e}}^{\mathrm{ss}}=\mathrm{P}_{\mathrm{e}}+\frac{\mathrm{V}_{\mathrm{s}} \mathrm{P}_{\mathrm{e}}}{\sqrt{\left(\mathrm{E}^{\prime}\right)^{2}+\left(\mathrm{V}_{\mathrm{b}}\right)^{2}-2 \mathrm{E}^{\prime} \mathrm{V}_{\mathrm{b}} \cos \delta}}$

It can be seen from Eq. 14 that the output electrical power flow can be controlled by a SSSC. With positive value of $\mathrm{V}_{\mathrm{s}}$, the output electrical power is increased whereas with negative value of $\mathrm{V}_{\mathrm{s}}$, the output electrical power is reduced.

Transient stability control: The transient stability of power system as shown in Fig. 2a can be expressed by following equations:

$\dot{\delta}=\omega$

$\dot{\omega}=\frac{1}{\mathrm{M}}\left[\mathrm{P}_{\mathrm{m}}-\mathrm{P}_{\mathrm{e}}\right]$ 
Here, $\delta, \omega$ and $\mathrm{P}_{\mathrm{m}}$ are the rotor angle, speed deviation, mechanical input power and moment of inertia, respectively of machine. The stability of the system can be improved by increasing the electrical output power when its speed deviation is positive and decreasing the power when speed deviation is negative. Thus the control strategy of SSSC is given by:

$\mathrm{V}_{\mathrm{s}}=\mathrm{k} \omega$

Here, $\mathrm{k}$ is constant gain control

\section{RESULTS}

The proposed model of power system equipped with a SSSC of Fig. 2a is investigated in this section. The system parameters are:

$\mathrm{M}=5.6, \mathrm{X}_{\mathrm{t}}=0.1, X_{d}^{\prime}=3, \mathrm{X}_{\mathrm{L} 1}=0.4, \mathrm{X}_{\mathrm{L} 2}=0.4, \mathrm{X}_{\mathrm{L} 3}=0.9$, $\mathrm{X}_{\mathrm{L} 4}=0.4, \mathrm{P}_{\mathrm{m}}=0.9$

It is considered that a 3-phase fault appears on line $\mathrm{L}_{1}$ and it is cleared by opening the faulted line. Figure 4 shows the swing curve of the system without $(K=0)$ and with various gains (K) OF a SSSC. Table 1 summarizes the maximum and minimum swing curve of Fig. 4.

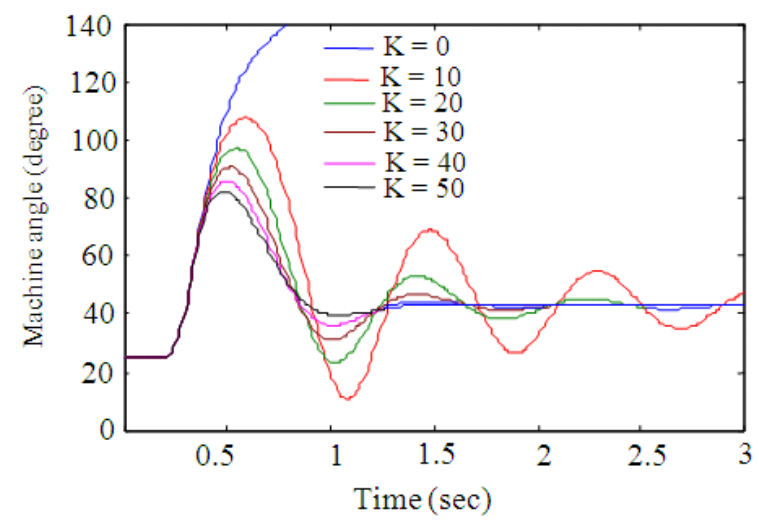

Fig. 4: Swing curve of the system without and with various gains of a $\mathrm{SSSC}$

Table 1: Maximum and minimum machine angle with various cases gains of SSSC

\begin{tabular}{lll}
\hline $\mathrm{K}$ & $\delta_{\max }($ degree $)$ & $\delta_{\min }($ degree $)$ \\
\hline 0 & - & - \\
10 & 177.68 & 10.99 \\
20 & 97.19 & 23.25 \\
30 & 90.55 & 31.05 \\
40 & 85.75 & 36.14 \\
50 & 82.14 & 39.36 \\
\hline
\end{tabular}

\section{DISCUSSION}

It can be observed from the simulation results that with $\mathrm{t}_{\mathrm{cl}}=120 \mathrm{msec}$ and without a $\operatorname{SSSC}(\mathrm{K}=0)$, the system is considered as unstable. However, with a $\mathrm{SSSC}$, the system is considered as stable. With $\mathrm{K}=10$, the maximum and minimum machine angle are 177.68 and 10.55 , respectively. The transient stability gets increase as the $\mathrm{K}$ is increased. With $\mathrm{K}=50$, the maximum and minimum machine angle are improved to 82.14 and 39.36 , respectively.

\section{CONCLUSION}

This study presents the method of improving transient stability of power system using a SSSC. The mathematical model of power system equipped with a SSSC is systematically derived. It was found that the power flow of the system can be control a series injected voltage of a SSSC. The stability of the power system can be controlled by a SSSC. This study uses machine speed deviation to control parameter of a SSSC. The simulation results are tested on a Single Machine Infinite bus system. The effect of gain control of a SSSC on stability improvement is also investigated. From the simulation results, it indicates that a SSSC can improve transient stability of the system and the stability of system gets increase when the gain control is increased.

\section{REFERENCES}

Al-Husban, A.N., 2009. An eigenstructure assignment for a static synchronous compensator. Am. J. Eng. Applied Sci., 2: 812-816. DOI: 10.3844/ajeassp.2009.812.816

Al-Rawi, N.M., A. Anwar and A.M. Abdul-Majeed, 2007. Computer aided transient stability analysis. J. Comput. Sci., 3: 149-153. DOI: 10.3844/jcssp.2007.149.153

Babainejad, S. and R. Keypour, 2010. Analysis of transient voltage stability of a variable speed wind turbine with doubly fed induction generator affected by different electrical parameters of induction generator. Trends Applied Sci. Res., 5: 251-278.

Chettih, S., M. Khiat and A. Chaker, 2008. Optimal distribution of the reactive power and voltages control in Algerian network using the genetic algorithm method. Inform. Technol. J., 7: 1170-1175. DOI: $10.3923 /$ itj.2008.1170.1175

Hannan, M.A. and K.W. Chan, 2006. Transient analysis of FACTS and custom power devices using phasor dynamics. J. Applied Sci., 6: 1074-1081. DOI: 10.3923/jas.2006.1074.1081 
Parry, M. and N. Gangatharan, 2005. Adaptive data transmission in multimedia networks. Am. J. Applied Sci., 2: 730-733. DOI: 10.3844/ajassp.2005.730.733

Sahoo, A.K., S.S. Dash and T. Thyagarajan, 2010. Power flow study including FACTS devices. J. Applied Sci., 10: 1563-1571. DOI: 10.3923/jas.2010.1563.1571
Seyed, A.T, H. Reza and N. Majid, 2008a. Comparison of different control strategies in GA-based optimized UPFC controller in electric power systems. Am. J. Eng. Applied Sci., 1: 45-52. DOI: 10.3844/ajeassp.2008.45.52

Seyed, A.T, H. Reza and N. Majid, 2008b. Decentralized controller design for static synchronous compensator using robust quantitative feedback theory method. Am. J. Eng. Applied Sci., 1: 66-75. DOI: 10.3844 /ajeassp.2008.66.75 